\title{
Ankle distraction arthroplasty using the llizarov external fixation and arthroscopy: first clinical experience
}

\author{
S.S. Leonchuk, L.A. Ostrovskikh, N.V. Sazonova
}

Ilizarov National Medical Research Centre for Traumatology and Orthopedics, Kurgan, Russian Federation

\begin{abstract}
We report a clinical case of a 27-year-old patient with posttraumatic painful ankle arthritis following sport injury treated with combined methods. The patient underwent ankle distraction arthroplasty with original Ilizarov apparatus and arthroscopic diagnosis and treatment of the ankle injury followed by the joint unloading and exercise therapy with frame on performed for 6 weeks at the Kurgan Ilizarov Center. The patient could improve pain relief and function at a long term following comprehensive treatment including surgical intervention, a course of physical procedures and exercise therapy. The combined technique can be used as an alternative treatment for patients with posttraumatic ankle arthritis.

Keywords: ankle joint, distraction arthroplasty, transosseous osteosynthesis, arthroscopy
\end{abstract}

\section{INTRODUCTION}

The incidence of ankle fractures is approximately 168-179 fractures per 100000 people each year $[1,2]$. Fractures of the lateral malleolus are the most common type of ankle fracture. These injuries generally occur in $55 \%$ of the cases resulting from falls in $61 \%$ and sports specific activities in $22 \%$ [2]. Patients with posttraumatic arthritis of the ankle are much younger than those with arthritis of the knee and the hip. Posttraumatic osteoarthritis (OA) of the ankle joint is reported to occur in $90 \%$ of the patients $[3,4]$ with an injury to the cartilage of the talus observed in all cases [5]. Intra-articular ankle fractures repaired with metal osteosynthesis are normally associated with an injury to the cartilage, impingement syndrome with resultant deformity and arthritis [6].

Posttraumatic ankle arthritis can be treated with two types of surgeries: (1) joint preservation procedures including arthroscopy, arthrotomy and debridement, distraction arthroplasty (DA), different osteochondral procedures, correcting osteotomies and (2) joint sacrificing interventions including arthrodesis or total ankle replacement [7]. Arthroscopy is a highly informative diagnostic procedure for posttraumatic ankle [6]. Arthroscopic diagnosis and treatment is the method of choice for radiologically non-verifiable osteochondral lesions of the talus due to ankle fractures [5]. Although some authors support the possibilities with articular regeneration the conditions necessary for this are very difficult to create [8].

There are no publications on ankle DA available in Russian peer reviewed journals, and most reports on ankle DA are in English. DA is reported to be effective in function improvement of patients with ankle arthritis [9-13]. The effectiveness of the technique was demonstrated in fundamental and clinical trials with increase in chondrocyte reparative capabilities in mechanical unloading of the joint [9-11, 14-16]. Arthrodiastasis allows for the articular surfaces being completely desintegrated during axial loading to improve subchondral sclerosis, subchondral bone cyst resorption, facilitating an environment for cartilage repair and pain relief [17]. DA allows alleviation of articular degeneration and delay of ankle arthroplasty or arthrodesis in severe ankle arthritis [10-12]. However, publications reporting failures with the technique $[9,18]$ and relative factors correlated with treatment failure with use of different approaches to ankle arthritis stimulates the search of new technical solutions. We present a clinical case with use of combined distractional external fixation and arthroscopy of the ankle.

\section{CLINICAL INSTANCE}

A 27-year-old patient presented with regular pain in the left ankle joint at the Kurgan Ilizarov Center (Fig. 1). He had a full range of motion in the ankle and experienced pain at the motion and palpation. $\mathrm{He}$ sustained sport related injury playing football 4 years ago and was diagnosed with bimalleolar fracture of the left tibia that was plated. The patient developed pain in the left ankle 8 months later that aggravated after walking long distances. Plates were removed at a local hospital and open debridement of the joint 
performed followed by several courses of physical procedures and drug therapy with no effect.

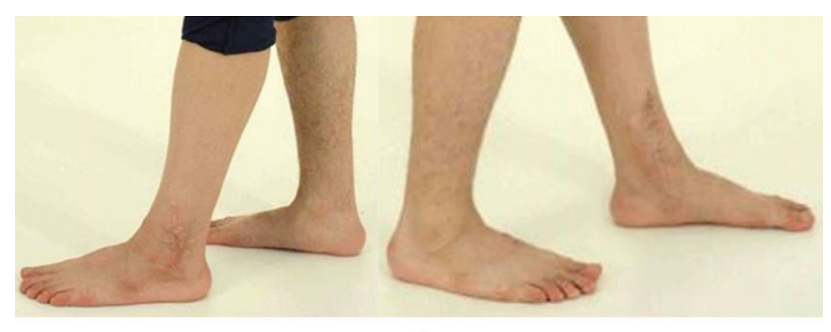

a

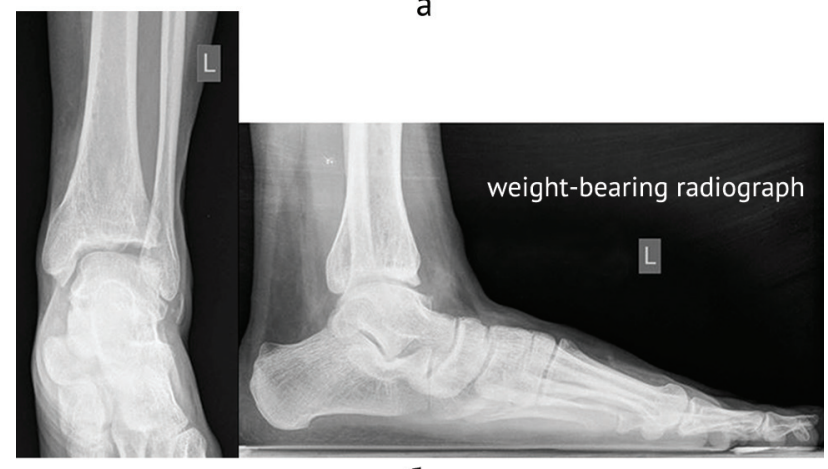

б

Fig. 1 Preoperative clinical appearance of the feet $(\boldsymbol{a})$ and radiographs of the left foot $(\boldsymbol{b})$ of patient $\mathrm{S}$.

The patient underwent comprehensive assessment at the Center including magnetic resonance images (MRI) that showed posttraumatic changes in the ankle joint. American Orthopaedic Foot and Ankle Society (AOFAS) scale for the hindfoot and the ankle was used to evaluate the segment function [19]. Preoperative AOFAS score was 47. Combined approach with distractional external fixation and arthroscopy of the ankle was offered for the patient considering the patient's history, clinical presentation, previous ankle surgeries in the records, MRI findings and our assertive experience with hybrid orthopaedic modalities. The surgery also aimed at maintaining the range of motion in the ankle joint with Ilizarov frame on.

\section{Surgical technique}

Distractional osteosynthesis of the left ankle joint was employed at the first stage (Fig. 2a). Two crossing wires were placed in mid tibia and three wires in the distal tibia including an olive wire driven in the tibia and the fibula. Tibial wires were fixed to the rings and tensioned. The rings were connected with upright rods. Two olive wires were placed in the heel with stoppers on both sides and a cantilever wire added. A wire was driven in the cuboid bone. The wires were fixed to the extended half-rings and tensioned. The Ilizarov frame was assembled and hinges mounted. The foot was fixed in a neutral position. Ankle distraction was produced intraoperatively with the forefoot distracted by $5.5 \mathrm{~mm}$ and the hindfoot distracted by $8 \mathrm{~mm}$ (Fig. 2b). Then the hinges were set loose for arthroscopic manipulations.

Standard arthroscopic set with pneumatic tourniquet applied to the distal femur was used for ankle arthroscopy. Stryker arthroscope (ø $4 \mathrm{~mm}$, $30^{\circ}$ ) was used for the procedure. Two conventional anteromedial and anterolateral portals were applied to approach the ankle. Arthroscopic image of the ankle (Fig. 3) demonstrated multiple adhesions, hyperemic synovium, claviform synovial papilla, hypertrophied cellular fat tissue being sclerotic in the lateral and medial pockets, grade II-III chondromalacia of the medial aspect of the talus, cartilage malacia in the posteromedial aspect of the talus, focal grade II chondromalacia of the central part of the talar dome, grade I-II chondromalacia of the lateral aspect of the tibial facet, grade II chondromalacia of the central tibial facet, multiple osteophytes, grade I chondromalacia at the notch of Harty. The adhesions were athroscopically excised, debridement of the tibial medial, lateral and central facet, the notch of Harty, chondroplasty of the talus and resection of osteophytes performed.
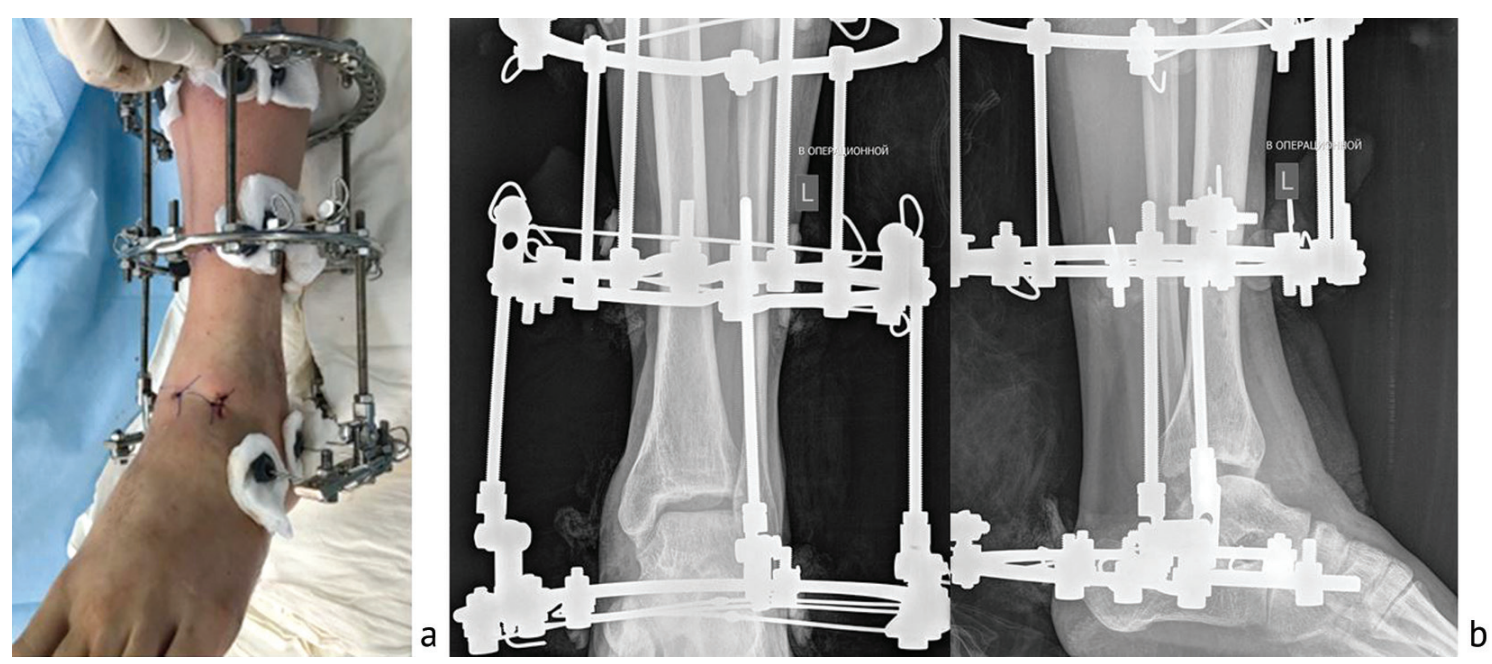

Fig. 2 Intraoperative photograph of the tibia and the foot $(\boldsymbol{a})$ and radiographs of the left foot $(\boldsymbol{b})$ 

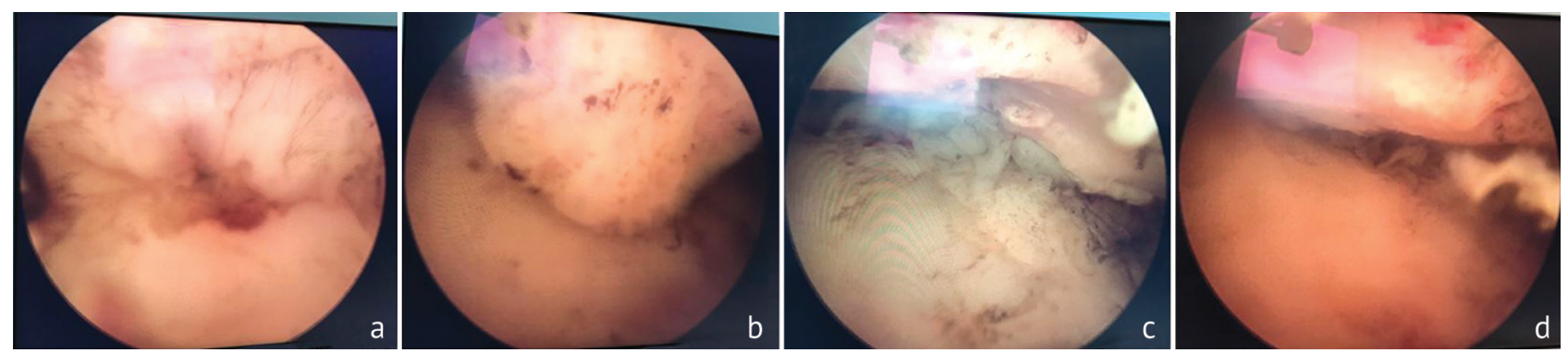

Fig. 3 Arthroscopic view of the ankle joint showing (a) adhesions at the entry to the joint, $(\boldsymbol{b})$ lateral malleolus with adhesions excised, $(c)$ defects and osteophytes on the articular surfaces of the talus and the tibia, $(\boldsymbol{d})$ appearance of the joint at the final stage of the procedure

No complications to vessels and nerves, pin site infection were observed after the treatment due to strict adhesion to methodological principles of transosseous osteosynthesis. Dressings were changed daily during the first postoperative week, then once every 10 14 days or as needed. Intravenous administration of cephalosporins, broad-spectrum antibiotics was used for prophylaxis during 7 days. The patient was encouraged to bear weight on the operated limb early after surgery. Different amount of distraction $(5.5 \mathrm{~mm}$ in the forefoot and $8 \mathrm{~mm}$ in the hindfoot) applied to the ankle joint did not affect the treatment in the first two weeks. After two weeks the Ilizarov frame was reassembled considering biomechanics of the joint and arthrodiastasis of $5.5 \mathrm{~mm}$ was provided for the foreand hind foot to allow exercise therapy for dorsal and planatar flexion. Overall ankle fixation with frame on was 6 weeks. With the frame taken off, the patient could continue exercise the joint and receive courses of physical procedure and massage. At one-year followup, the patient maintained the foot position (Fg. 4), experienced pain relief and ankle function scored 90 on AOFAS scale, and he could return to active life style and sports. Radiographs showed no changes in space of the operated ankle joint. The patient maintained full range of motion in the joint with no pain.
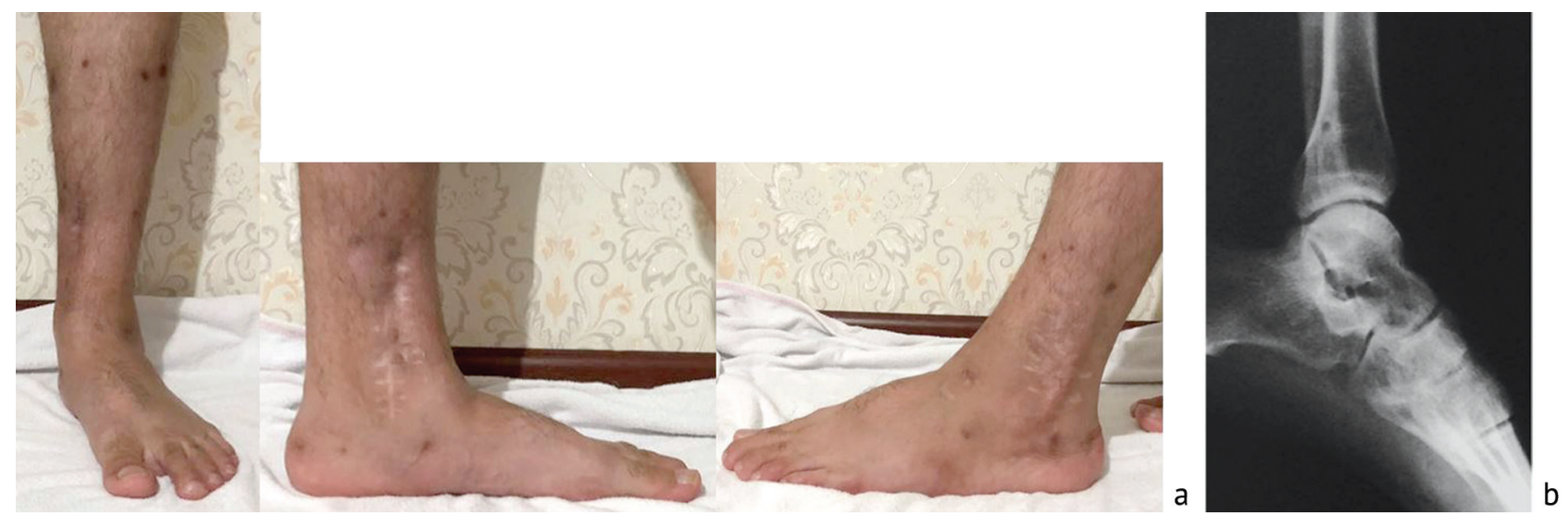

Fig. 4 Clinical appearance of the left foot (a) and radiographs of the ankle joint $(\boldsymbol{b})$ at one-year follow-up

\section{DISCUSSION}

Posttraumatic osteoarthritis of the ankle joint is common among young population and the best treatment strategy is controversial [20]. Arthroscopic diagnosis and treatment are reported as minimally invasive and highly informative procedure facilitating improvement of the function and quality of life for patients with posttraumatic arthritis of the ankle [5, 6]. Posttraumatic injury to the cartilage of different severity occur in all cases [5] and can be addressed with microdamage procedures, auto- and allografts to repair cartilage defects of tibia or talus, en block allografts to repair greater part of the talus [21]. Although some authors support the possibilities with articular regeneration the conditions necessary for this are very difficult to create [8]. Arthroscopy of the ankle can be associated with complications like in any invasive procedure, and adverse events are reported to occur in $6.6-12.6 \%$ of the patients with injuries to nerves, vessels, ligaments, and infection [22-26]. DA of the ankle combined with external fixation was shown to be a safe surgical approach facilitating improvement of degeneration and delay of total ankle replacement and arthrodesis [9-13]. Tellisi N. et al. described DA in a retrospective review of patients with ankle 
arthritis [12]. DA was shown to improve metabolism of proteoglycans in the cartilage, help resolve inflammation, cartilage atrophy and osteochondral defects at the weight-bearing area [14-17]. The procedure provides pain relief, improved function, increased articular space decreasing subchondral bone density [9-13]. Arthrodiastasis allows for the articular surfaces being completely desintegrated during axial loading to improve subchondral sclerosis, subchondral bone cyst resorption, facilitating an environment for cartilage repair and pain relief [17]. However, publications report failures in DA in $21.7-28.0 \%$ of the cases $[9,18]$ stimulating the search of new technical solutions. The combination of distractional transosseous osteosynthesis and arthroscopy can be used as an alternative method of treatment of posttraumatic ankle arthritis.

Several issues of DA are under consideration in the foreign literature. One of the questions to be answered is what size of the ankle space is to measure? There are different opinions regarding this matter. The articular distraction can measure at least $5 \mathrm{~mm}[11,13,17,18]$ or more than $5 \mathrm{~mm}$ because the space is supposed to decrease at weight-bearing. Fragomen A.T. et al. [27] recommended distraction of at least $5.8 \mathrm{~mm}$ and it can reach as mich as $10 \mathrm{~mm}$ to avoid a contact between articular surfaces. In our case, different amount of distraction $(5.5 \mathrm{~mm}$ in the forefoot and $8 \mathrm{~mm}$ in the hindfoot) applied to the ankle joint did not affect the treatment in the first two weeks at a long term. After two weeks the Ilizarov frame was reassembled to replace hinges in the Inman plane [28] to allow exercise therapy for dorsal and planatar flexion with the fixator on. Another question is how long the distraction is to be performed with external fixation device. Zhao H. [9] reported Ilizarov ankle fixation for 3 months, and the patient was encouraged to maintain full weight-bearing on the operated limb 2 weeks after surgery. Similar period of fixation is reported by different authors [10, 12, 18]. Ankle distraction and exercise therapy with Ilizarov frame on lasted for six weeks in our patient.

Complications associated with transosseous osteosynthesis and DA are reported by many authors $[9,10,12,13,18]$. Zhao H. reported pin tract infection in 14 cases out of $46(30.4 \%)$ that were treated with regularly changed dressings, oral or intravenous administration of antibiotics without premature removal of external fixator in the cases [9]. Neither fractures nor serious injury to nerves and vessels were reported by Zhao H. et al. Marijnissen A.C. [18] reported pin tract infection in $14 \%$ of the patients who were treated with antibiotics, and the adverse event did not affect the length of ankle distraction. Xu Y. [10] described $12.5 \%$ of patients who developed pin tract infection that was addressed with antibiotics and regular dressings. We observed no injury to vessels and nerves, pin tract infection in our case due to strict adhesion to methodological principles of transosseous osteosynthesis. Pagenstert G. [29] reported improved gait and overall activity level due to pain relief in treatment of ankle arthritis and no correlations were seen with range of motion in the ankle. This was confirmed by our clinical instance. The patient maintained full range of motion in the ankle joint and developed greater activity level due to improved pain. Some publications feature increased ankle space following DA [9-13]. In our case, the ankle space showed similar measurements at a long term. Zhao $\mathrm{H}$. et al. [9] reviewed outcomes of 46 patients with ankle arthritis treated with DA and found no correlation between failure and gender, or overweight, or side, or age, or type and stage of osteoarthritis, or pin tract infection in transosseous osteosynthesis.

\section{CONCLUSION}

The clinical instance has shown the possibility of achieving a positive outcome in treatment of posttraumatic ankle arthritis with combined use of distractional transosseous osteosynthesis and arthroscopy. The approach can be used as an alternative treatment for patients with posttraumatic ankle arthritis in the availability of an experienced surgical team.

The authors declare that there is no conflict of interest.

The authors received no specific funding for this work.

\section{REFERENCES}

1. Juto H., Nilsson H., Morberg P. Epidemiology of Adult Ankle Fractures: 1756 cases identified in Norrbotten County during 2009-2013 and classified according to AO/OTA. BMC Musculoskelet. Disord., 2018, vol. 19, no. 441. DOI: 10.1186/s12891-018-2326-x

2. Elsoe R., Ostgaard S.E., Larsen P. Population-based epidemiology of 9767 ankle fractures. Foot Ankle Surg., 2018, vol. 24, no. 1, pp. 34-39. DOI: $10.1016 /$ j.fas.2016.11.002

3. Richmond S.A., Fukuchi R.K., Ezzat A., Schneider K., Schneider G., Emery C.A. Are joint injury, sport activity, physical activity, obesity, or occupational activities predictors for osteoarthritis? A systematic review. J. Orthop. Sports Phys. Ther., 2013, vol. 43, no. 8, pp. 515-B19. DOI: $10.2519 /$ jospt.2013.4796 
4. Weatherall J.M., Mroczek K., McLaurin T., Ding B., Tejwani N. Post-traumatic ankle arthritis. Bull. Hosp. Jt. Dis., 2013, vol. 71, no. 1, pp. 104-112.

5. Brizhan L.K., Iurmina N.S., Slivkov K.A., Kerimov A.A. Khirurgicheskaia profilaktika posttravmaticheskogo kruzartroza u patsientov s perelomami lodyzhek [Surgical prevention of posttraumatic crusarthrosis in patients with malleolar fractures]. Vestnik Natsionalnogo Mediko-khirurgicheskogo Tsentra im. N.I. Pirogova, 2018, vol. 13, no. 1, pp.79-84. (in Russian)

6. Gorodnichenko A.I., Semenov A.I., Minaev A.N. Artroskopiia v diagnostike i lechenii posttravmaticheskogo deformiruiushchego artroza golenostopnogo sustava [Arthroscopy in diagnosis and treatment of posttraumatic arthrosis deformans of the ankle]. Kremlevskaia Meditsina. Klinicheskii Vestnik, 2015, no. 3, pp. 71-74. (in Russian)

7. Barg A., Pagenstert G.I., Horisberger M., Paul J., Gloyer M., Henninger H.B., Valderrabano V. Supramalleolar osteotomies for degenerative joint disease of the ankle joint: indication, technique and results. Int. Orthop., 2013, vol. 37, no. 9, pp. 1683-1695. DOI: 10.1007/s00264-013-2030-2.

8. Minas T., Peterson L. Advanced techniques in autologous chondrocyte transplantation. Clin. Sports Med., 1999, vol. 18, no. 1, pp. 13-44, v-vi.

9. Zhao H., Qu W., Li Y., Liang X., Ning N., Zhang Y., Hu D. Functional analysis of distraction arthroplasty in the treatment of ankle osteoarthritis. J. Orthop. Surg. Res., 2017, vol. 12, no. 1, pp. 18. DOI: 10.1186/s13018-017-0519-X

10. Xu Y., Zhu Y., Xu X.Y. Ankle joint distraction arthroplasty for severe ankle arthritis. BMC Musculoskelet. Disord., 2017 , vol. 18 , no. 1, pp. 96. DOI: $10.1186 / \mathrm{s} 12891-017-1457-9$

11. Lamm B.M., Gourdine-Shaw M. MRI evaluation of ankle distraction: a preliminary report. Clin. Podiatr. Med. Surg., 2009, vol. 26, no. 2, pp. 185191. DOI: $10.1016 /$ j.cpm.2008.12.007

12. Tellisi N., Fragomen A.T., Kleinman D., O'Malley M.J., Rozbruch S.R. Joint preservation of the osteoarthritic ankle using distraction arthroplasty. Foot Ankle Int., 2009, vol. 30, no. 4, pp. 318-325. DOI: 10.3113/FAI.2009.0318

13. Paley D., Lamm B.M., Purohit R.M., Specht S.C. Distraction arthroplasty of the ankle - how far can you stretch the indications? Foot Ankle Clin., 2008, vol. 13, no. 3, pp. 471-484. DOI: 10.1016/j.fcl.2008.05.001

14. Kajiwara R., Ishida O., Kawasaki K., Adachi N., Yasunaga Y., Ochi M. Effective repair of a fresh osteochondral defect in the rabbit knee joint by articulated joint distraction following subchondral drilling. J. Orthop. Res., 2005, vol. 23, no. 4, pp. 909-915. DOI: 10.1016/j.orthres.2004.12.003

15. Nishino T., Chang F., Ishii T., Yanai T., Mishima H., Ochiai N. Joint distraction and movement for repair of articular cartilage in a rabbit model with subsequent weight-bearing. J. Bone Joint Surg. Br., 2010, vol. 92, no. 7, pp. 1033-1040. DOI: 10.1302/0301-620X.92B7.23200

16. Van Valburg A.A., Van Roermund P.M., Marijnissen A.C., Wenting M.J., Verbout A.J., Lafeber F.P., Bijlsma J.W. Joint distraction in treatment of osteoarthritis (II): effects on cartilage in a canine model. Osteoarthritis Cartilage, 2000, vol. 8, no. 1, pp. 1-8. DOI: 10.1053/joca.1999.0263

17. Intema F., Thomas T.P., Anderson D.D., Elkins J.M., Brown T.D., Amendola A., Lafeber F.P., Saltzman C.L. Subchondral bone remodeling is related to clinical improvement after joint distraction in the treatment of ankle osteoarthritis. Osteoarthritis Cartilage, 2011, vol. 19, no. 6, pp. 668-675. DOI: $10.1016 /$ j.joca.2011.02.005

18. Marijnissen A.C., Van Roermund P.M., Van Melkebeek J., Schenk W., Verbout A.J., Bijlsma J.W., Lafeber F.P. Clinical benefit of joint distraction in the treatment of severe osteoarthritis of the ankle: proof of concept in an open prospective study and in a randomized controlled study. Arthritis Rheum., 2002, vol. 46, no. 11, pp. 2893-2902. DOI: 10.1002/art.10612

19. Kitaoka H.B., Alexander I.J., Adelaar R.S., Nunley J.A., Myerson M.S., Sanders M. Clinical rating systems for the ankle-hindfoot, midfoot, hallux, and lesser toes. Foot Ankle Int., 1994, vol. 15, no. 7, pp. 349-353

20. Rivera J.C., Beachler J.A. Distraction arthroplasty compared to other cartilage preservation procedures in patients with post-traumatic arthritis: a systematic review. Strategies Trauma Limb Reconstr., 2018, vol. 13, no. 2, pp. 61-67. DOI: 10.1007/s11751-018-0305-2

21. Wiewiorski M., Barg A., Valderrabano V. Chondral and osteochondral reconstruction of local ankle degeneration. Foot Ankle Clin., 2013, vol. 18, no. 3, pp. 543-554. DOI: 10.1016/j.fc1.2013.06.009.

22. Deng D.F., Hamilton G.A., Lee M., Rush S., Ford L.A., Patel S. Complications associated with foot and ankle arthroscopy. J. Foot Ankle Surg., 2012, vol. 51, no. 3, pp. 281-284. DOI: 10.1053/j.jfas.2011.11.011

23. Galla M., Lobenhoffer P. Technique and results of arthroscopic treatment of posterior ankle impingement. Foot Ankle Surg., 2011, vol. 17, no. 2, pp. 79-84. DOI: 10.1016/j.fas.2010.01.004

24. Nickisch F., Barg A., Saltzman C.L., Beals T.C., Bonasia D.E., Phisitkul P., Femino J.E., Amendola A. Postoperative complications of posterior ankle and hindfoot arthroscopy. J. Bone Joint Surg. Am., 2012, vol. 94, no. 5, pp. 439-446. DOI: 10.2106/JBJS.K.00069

25. Unger F., Lajtai G., Ramadani F., Aitzetmüller G., Orthner E. Arthroscopy of the upper ankle joint. A retrospective analysis of complications. Unfallchirurg, 2000, vol. 103, no. 10, pp. 858-863. DOI: 10.1007/s001130050633

26. Young B.H., Flanigan R.M., DiGiovanni B.F. Complications of ankle arthroscopy utilizing a contemporary noninvasive distraction technique. J. Bone Joint Surg. Am., 2011, vol. 93, no. 10, pp. 963-968. DOI: 10.2106/JBJS.I.00977

27. Fragomen A.T., McCoy T.H., Meyers K.N., Rozbruch S.R. Minimum distraction gap: how much ankle joint space is enough in ankle distraction arthroplasty? HSS J., 2014, vol. 10, no. 1, pp. 6-12. DOI: 10.1007/s11420-013-9359-3

28. Isman R.E., Inman V.T. Anthropometric studies of the human foot and ankle. Bulletin of Prosthetics Research, 1969, vol. 10, pp. 97-129.

29. Pagenstert G., Leumann A., Hintermann B., Valderrabano V. Sports and recreation activity of varus and valgus ankle osteoarthritis before and after realignment surgery. Foot Ankle Int., 2008, vol. 29, pp. 985-993. DOI: 10.3113/FAI.2008.0985

Received: 19.03.2019

\section{Information about the authors:}

1. Sergei S. Leonchuk, M.D., Ph.D.,

Ilizarov National Medical Research Centre for Traumatology and Orthopedics, Kurgan, Russian Federation, Email: leon4yk@mail.ru

2. Larisa A. Ostrovskikh, M.D.,

Ilizarov National Medical Research Centre for Traumatology and Orthopedics, Kurgan, Russian Federation

3. Natalia V. Sazonova, M.D., Ph.D.,

Ilizarov National Medical Research Centre for Traumatology and Orthopedics, Kurgan, Russian Federation 